\title{
Ischaemic brain changes associated with catheter-based diagnostic cerebral angiography: a diffusion-weighted imaging study
}

\author{
Turkan Ikizceli ${ }^{1 A, B, D, E, F}$, Halil Donmez ${ }^{2 D, F}$, Servet Kahvecij ${ }^{3 C, F}$, Guven Kahriman ${ }^{4 E}$ \\ ${ }^{1}$ Haseki Training and Research Hospital, Istanbul, Turkey \\ ${ }^{2}$ Erciyes University, Kayseri, Turkey \\ ${ }^{3}$ Umm Slah Health Center, Turkey \\ ${ }^{4}$ Erciyes University, Kayseri, Turkey
}

\section{Abstract}

Purpose: This study aims to evaluate the incidence of clinically silent embolic cerebral infarctions and associated risk factors following diagnostic cerebral angiography with diffusion-weighted imaging (DWI).

Material and methods: A total of 71 cerebral digital subtraction angiograms (42 male, 29 female, average age: $56.0 \pm 15.0)$ obtained using nonionic contrast material were prospectively evaluated. To assess embolic events, before and after (1-3 days) angiography, DWI was performed. The risk factors for embolic ischemic brain changes such as the patient's age and sex, atherosclerotic vessel wall disease, type of indication for catheter angiography, the number and size of the catheters, anatomic variants, selective/nonselective catheterization, contrast media volume, and time of procedure were determined. Fisher's exact tests and Student t-tests were used for the statistical analyses of outcomes.

Results: Thirteen new silent ischemic lesions were identified in 7 out of 71 patients who underwent diagnostic cerebral angiography. Embolic cerebral lesions were often 6-10mm in diameter. According to the findings in this study, there was a strong correlation between diffusion abnormality and patient age, which was considered risk factors $(p<0.05)$. However, there were no significant correlations between other risk factors and the lesions' appearance $(p>0.05)$.

Conclusions: In elderly patients, the angiographic procedures should be performed meticulously and DWI in all patients obtained routinely, even if the regular neurological examination shows they are healthy. In this way, the presence of microemboli and clinical results can be evaluated.

Key words: ischemia, cerebral angiography, embolism, diffusion-weighted imaging.

\section{Introduction}

Diagnostic angiography is an imaging modality accepted as the gold standard for vascular system imaging. Advancements in catheter technology and the digital subtraction angiography (DSA) technique have decreased the invasiveness and enabled the procedure to become minimally invasive [1]. In several studies, however, it has been reported that asymptomatic embolism also may oc- cur with cerebral angiography. Patient age, sex, vascular structure and anatomical variants, and many risk factors related to the procedure were reported for such embolic events [2]. Assessment of peri-procedural embolic complications was based on neurological examination findings. It is possible to detect embolic events presenting such neurological symptoms. With diffusion-weighted imaging (DWI), which is highly sensitive to acute ischaemic cerebral changes, there is a chance to define not only

Correspondence address:

Dr. Turkan Ikizceli, Department of Radiology, University of Health Sciences, Istanbul Haseki Training and Research Hospital, Haseki Sultan,

Adnan Adivar Street, 34096 Fatih/lstanbul, Turkey, e-mail: turkan.ikizceli@sbu.edu.tr

Authors' contribution:

A Study design · B Data collection · C Statistical analysis · D Data interpretation · E Manuscript preparation · F Literature search · G Funds collection 
macro embolic events showing clinical symptoms but also micro embolic events. These occur more commonly and are mostly subclinical, and thus more comprehensive information about actual sizes of the embolic events can be gained due to the procedure $[2,3]$.

The objective of this study was to investigate the incidence of acute emerging cerebral ischaemic lesions on DWI following diagnostic cerebral angiography and possible correlations between the risk factors defined related to the patient, vascular system, procedure, and DWI positivity.

\section{Material and methods}

\section{Study population}

This study was prospectively conducted between November 2009 and September 2010. Patients who required DSA to diagnose cerebrovascular diseases such as aneurysm, arteriovenous fistula, and ischaemic cerebral attack were included in the study. The following patient groups were excluded from the study: patients requiring emergency DSA but without time for DWI, patients requiring any intracranial endovascular interventions (embolization, stenting, balloon angioplasty), patients with claustrophobia, patients under 18 years of age, and patients who did not consent. Seventy-one patients who underwent diagnostic angiography were included in the study. Forty-two of the patients were male and 29 were female, aged between 22 and 83 years, with a mean age of $56.0 \pm 15.0$ years. All the patients included in the study underwent only DWI pre-operation and post-operation within the same day.

The study was approved by the Ethics Board of Erciyes University (Number: 2009/126).

\section{Study protocol}

DWI examinations were performed with a 1.5 T magnetic resonance scanner (Gyroscan Intera Release Philips, Netherlands). Diffusion-weighted images were acquired through multi-sectioned, single-shot, spin-echoed, and EPI sequences. Diffusion gradients were applied using 2 different ' $b$ ' values $\left(b=0 \mathrm{~s} / \mathrm{mm}^{2}\right.$ and $\left.b=1000 \mathrm{~s} / \mathrm{mm}^{2}\right)$ in $\mathrm{x}, \mathrm{y}$, and $\mathrm{z}$ directions. Imaging parameters were $\mathrm{TE}=145$, FoV $=260 \times 260 \mathrm{~mm}, 128 \times 96$ matrix, intersection thickness $=5 \mathrm{~mm}$, and intersection gap $=1 \mathrm{~mm}$. The scanner automatically created ADC maps of the isotropic images.

Angiography processes were carried out with cerebral DSA (Philips Integris 5000, Philips Medical Systems, Netherlands) devices. Anticoagulant therapy was discontinued a day before the procedure in heparinized patients because the patients' DSA processes were planned under elective conditions. A preparation including 25,000 IU/ 5 heparin sodium (Nevparin ${ }^{\circledR}$, Mustafa Nevzat İlaç San. Istanbul, Turkey) was added at $1000 \mathrm{IU} / 1000 \mathrm{~mL}$ to the catheter cleaning solution of all patients. A nonionic con- trast agent (Ultravist 370/100, Schering, Berlin, Germany) was used in correct doses $(0.2-6 \mathrm{ml} / \mathrm{kg})$ according to the patient's age and weight, and the amount of the given agents was recorded for all patients. The contrast agent was injected with an automatic injection device with a rate of $15-30 \mathrm{ml} / \mathrm{s}$ in arcus aortography, 6-12 ml/s in nonselective CCA catheterization, and $5-10 \mathrm{ml} / \mathrm{s}$ in selective ICA catheterization, filming until the late phases. Pulse number, arterial blood pressure, and carbon dioxide and oxygen saturation were monitored in all patients during the procedure. Arcus and bovine type arcus were defined for all patients. A standard 0.035-inch guidewire (Radifocus, 0.035 inch diameter, Terumo, Tokyo, Japan) and a 5F Simmons 2 (5-F, $100 \mathrm{~cm}$ length, SIM2 Super Torque; Cordis Corporation, Miami Lakes, USA) (SIM2) or 5F Headhunter (Cordis Neurovascular, Miami Lakes, USA) (H1) were used as catheters according to the arcus type.

Arterial images of the cerebral carotid system were obtained in a routine projection by selective introduction into the ICA or non-selective catheterization of CAA in the patients with ICA stenosis. The procedure duration started with femoral artery access and ended with removal of the last used catheter, and this duration was recorded for all patients. A single academic neuroradiologist performed all the angiography processes.

\section{Data collection}

Two separate radiologists randomly assessed DWI outcomes. Hyperintensities on DWI were classified as $6<\mathrm{mm}$, 6-10 $\mathrm{mm}$, and $>10 \mathrm{~mm}$ for acute emerged ischaemic lesions corresponding to "low ADC values" on ADC maps. For lesion numbers, the presence of 1 lesion was considered single, while 2 or more were considered multiple. The lesions were described as cortical, subcortical, and white matter lesions regarding their location. Moreover, the vascular distribution of the lesions was defined. The patients were assessed as 2 groups: DWI positive and DWI negative, and risk parameters for embolic ischaemic lesion development were defined as 1) patient characteristics (age, sex);2) additional problems related to the vascular system complicating catheter manipulation and the procedure, such as the presence of atherosclerotic plaque and severe anatomic conditions, including tortuosity, angled ICA outlet, and arcus types (bovine type arcus, type 2 and type 3 arcus); and 3) procedure-related parameters (specifications of the catheter used, selective or nonselective ICA catheterization, amount of the contrast agent used, and procedure duration).

\section{Statistical analysis}

SPSS for Windows 15.0 software was used for the statistical analysis. The patients with and without lesions were compared according to the diffusion findings in terms of the parameters, investigating the possible risk factors for 

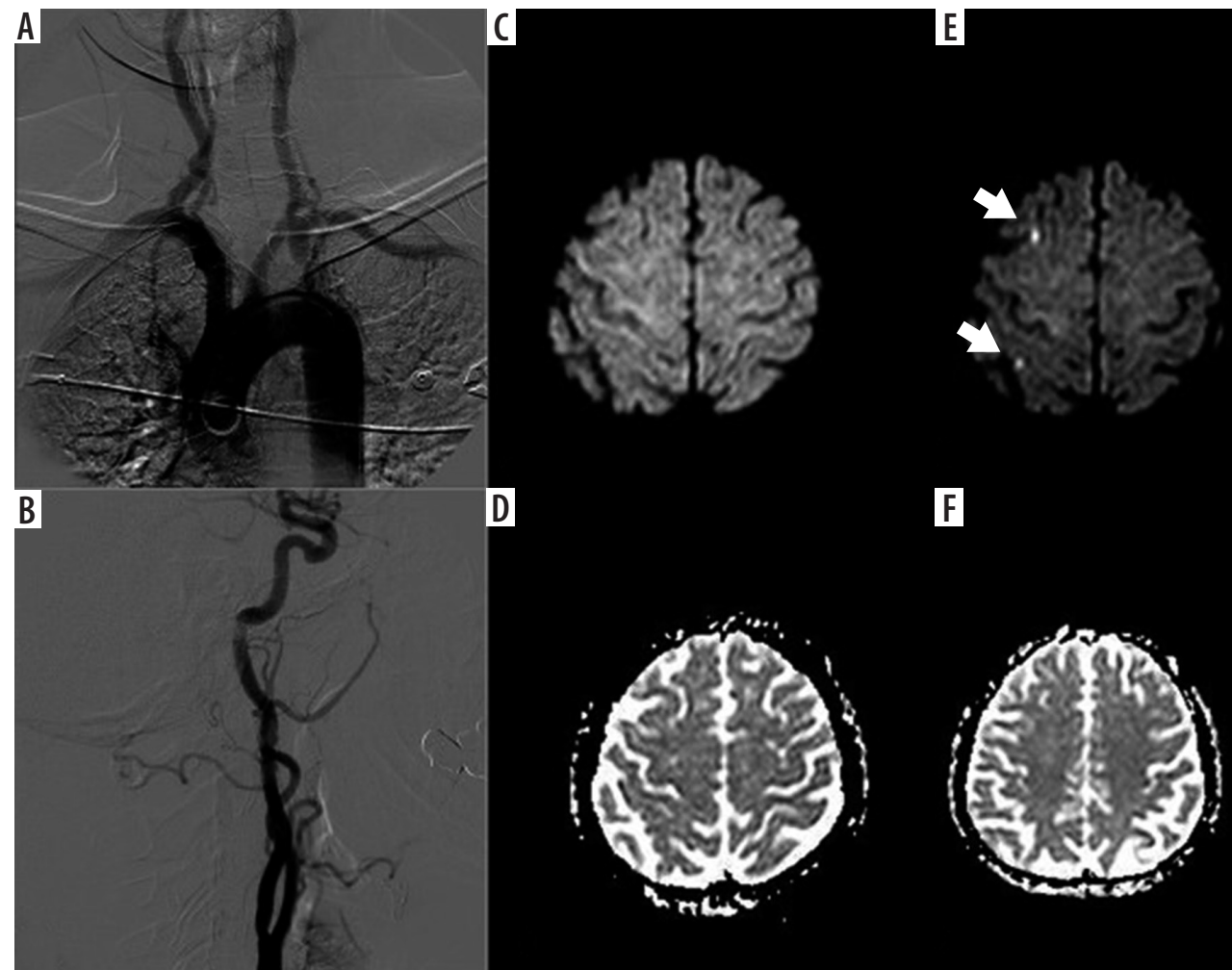

F
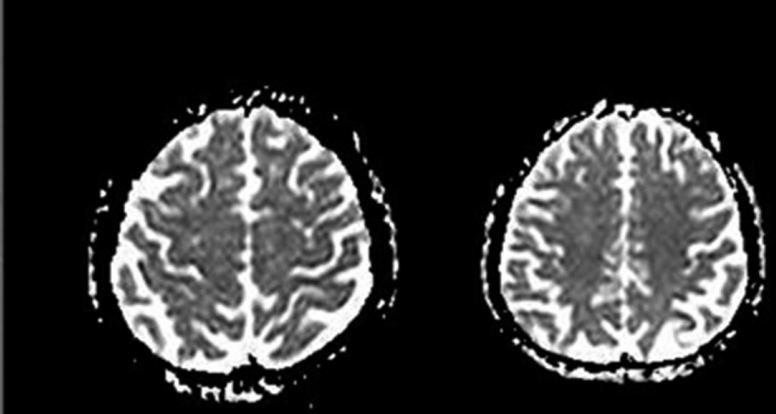

Figure 1. A, B) A 63-year-old female using an $\mathrm{H} 1$ catheter. Angiographic images with short segment atherosclerosis of the type-2 arcus aorta and right Internal carotid artery bulbs. Diffusion-weighted imaging - before the procedure (C, D) and after the procedure (E, F). Two subcortical acute ischaemic lesions (arrows) in the middle cerebral artery territories on the right side
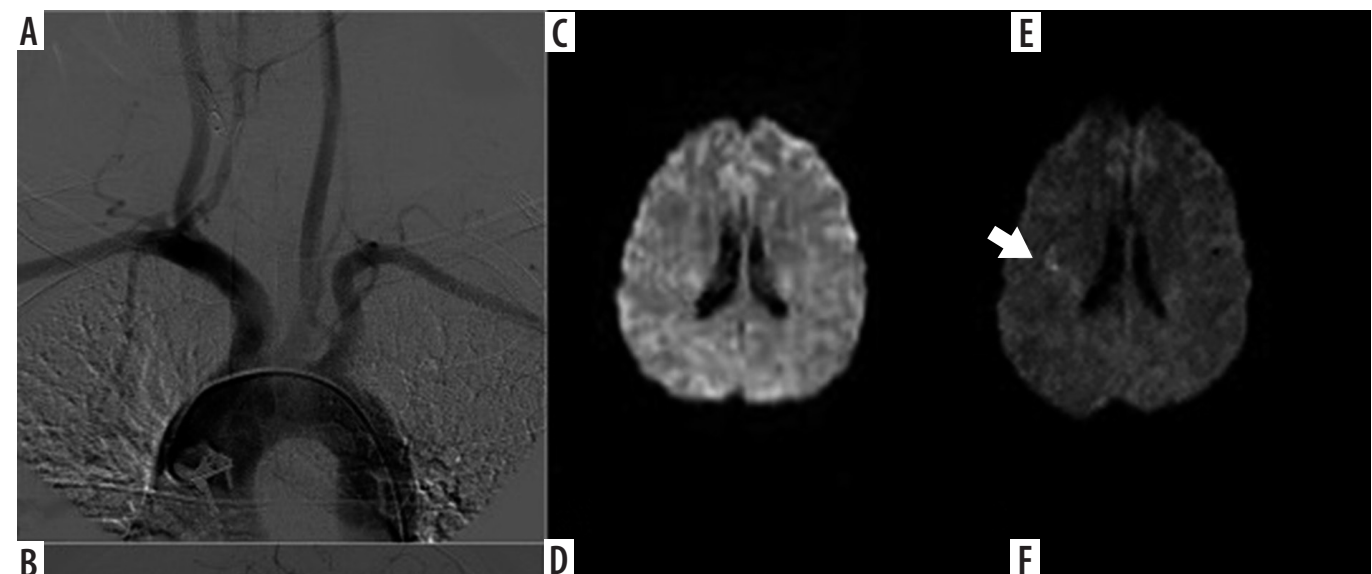

B

D

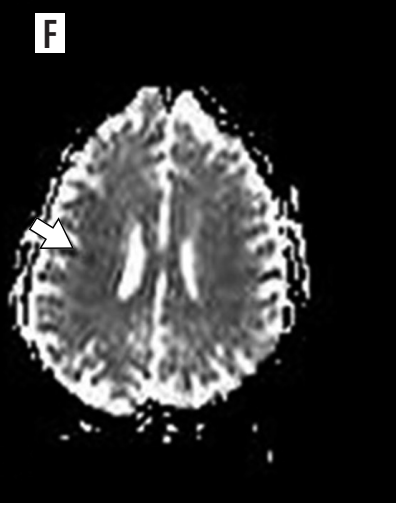

Figure 2. A, B) A 50-year-old female using an $\mathrm{H} 1$ catheter; Angiographic images type-1 arch aorta and an aneurysm in the anterior cerebral artery localization. Diffusion-weighted imaging; before the procedure (C, D) and after the procedure (E, F). Acute ischaemic lesion (arrow) in the middle cerebral artery territories on the right side 
Table 1. General characteristics of the lesions on diffusion-weighted imaging

\begin{tabular}{|c|c|c|}
\hline Factor & $n$ & $\%$ \\
\hline \multicolumn{3}{|l|}{ Location } \\
\hline Cortical and subcortical & 9 & 69.2 \\
\hline White matter & 4 & 30.8 \\
\hline \multicolumn{3}{|l|}{ Vascular distribution } \\
\hline MCA & 9 & 69.2 \\
\hline Border zone & 3 & 23.1 \\
\hline ACA & 1 & 7.7 \\
\hline \multicolumn{3}{|l|}{ Number of lesions } \\
\hline Single (1) & 8 & 61.5 \\
\hline Multiple (> 2) & 5 & 38.5 \\
\hline \multicolumn{3}{|l|}{ Size } \\
\hline$\leq 5 \mathrm{~mm}$ & 4 & 30.8 \\
\hline $6-10 \mathrm{~mm}$ & 7 & 53.9 \\
\hline$>10 \mathrm{~mm}$ & 2 & 15.4 \\
\hline
\end{tabular}

MCA - middle cerebral artery, ACA - anterior cerebral artery

embolic ischaemia development. Categorical variables such as sex, age, atherosclerosis, anatomical variants, selectivity, and catheter type were expressed as number $(n)$ and percentage (\%), while the continuous variables such as age, sex, procedure duration, and the amount of the contrast agent were stated as mean \pm standard deviation (mean $\pm \mathrm{SD}$ ). Comparison of categorical variables was carried out using chi-square independence tests (Pearson's $\chi^{2}$, continuity correction, and Fischer's exact). In contrast,
Student's $t$-test was used to compare the continuous variables. $P$-values $<0.05$ were considered statistically significant in all analyses.

\section{Results}

When examining the patients for their clinical indications, the most common cause of diagnostic angiography was atherosclerotic vascular disease in 22 patients, cerebrovascular diseases (CVD) in 19 patients, and vascular lesion in 16 patients.

\section{Diffusion-weighted imaging findings}

Following the procedure, an acute emerged ischaemic lesion that corresponded to a "low ADC value" on ADC maps and hyperintense on DWI was observed in $9.9 \%$ $(n=7)$ of the patients. All the lesions found on DWI were silent ischaemia without clinical symptoms. The lesion number in 7 positive diffusion patients was 13, and the median lesion load per diffusion positive patient was 2 (1-4). Of the lesions, $69.2 \%(n=9)$ had cortical and subcortical localization, $69.2 \%(n=9)$ were in the middle cerebral artery (MCA) irrigation area (Figures 1 and 2), $61.5 \%(n=8)$ had single lesions, and the lesion sizes of $53.9 \%(n=7)$ of patients were between 6 and $10 \mathrm{~mm}$ (Table 1).

When considering the distribution of the patients with newly developed lesions regarding the clinic indications, new lesions developed in 3 patients from the diagnostic angiography group due to atherosclerotic vascular disease. Next, new lesions developed in 2 patients from the

Table 3. Characteristics of the patients with and without new lesions on diffusion-weighted imaging

\begin{tabular}{|c|c|c|c|c|c|c|}
\hline \multicolumn{3}{|l|}{ Factor } & New lesion & No lesion & Total & $p$ \\
\hline \multirow{2}{*}{\multicolumn{2}{|c|}{ Sex, $n(\%)$}} & Male & $4(57.1)$ & $38(59.4)$ & $42(59.2)$ & \multirow[t]{2}{*}{$>0.05$} \\
\hline & & Female & $3(42.9)$ & $26(40.6)$ & $29(40.8)$ & \\
\hline \multicolumn{3}{|l|}{ Age $($ mean $\pm S D)$} & $66.4 \pm 11.8$ & $53.7 \pm 14.9$ & $56.0 \pm 15.0$ & $<0.05$ \\
\hline \multirow{2}{*}{\multicolumn{2}{|c|}{ Catheter type, $n(\%)$}} & $\mathrm{H} 1$ & $2(28.6)$ & $31(48.4)$ & $33(46.5)$ & \multirow[t]{2}{*}{$>0.05$} \\
\hline & & SIM2 & $5(71.4)$ & $33(51.6)$ & $38(53.5)$ & \\
\hline \multirow{2}{*}{\multicolumn{2}{|c|}{ Selectivity, $n(\%)$}} & Nonselective & $3(42.9)$ & $24(37.5)$ & $27(38)$ & \multirow[t]{2}{*}{$>0.05$} \\
\hline & & Selective & $4(57.1)$ & $40(62.5)$ & $44(62)$ & \\
\hline \multirow[t]{7}{*}{ Anatomical features, $n(\%)$} & \multirow{5}{*}{$\begin{array}{l}\text { Aortic } \\
\text { type }\end{array}$} & Normal & $4(57.1)$ & $41(64.1)$ & $45(63.4)$ & \multirow[t]{7}{*}{$>0.05$} \\
\hline & & Bovine & $4(57.1)$ & $23(35.9)$ & $26(36.6)$ & \\
\hline & & Type 1 & $2(28.6)$ & $44(68.7)$ & $46(64.8)$ & \\
\hline & & Type 2 & $4(57.1)$ & $17(26.6)$ & $21(29.6)$ & \\
\hline & & Type 3 & $1(14.3)$ & $3(4.7)$ & $4(5.6)$ & \\
\hline & \multirow[t]{2}{*}{ Tortuosity } & No & $5(71,4)$ & $45(70,3)$ & $50(70,4)$ & \\
\hline & & Yes & $2(28,6)$ & $19(29,7)$ & $21(29,6)$ & \\
\hline \multicolumn{3}{|c|}{ Contrast volume $(\mathrm{ml})$, mean \pm SD } & $139.2 \pm 55.9$ & $148.9 \pm 36.2$ & $148 \pm 37.9$ & $>0.05$ \\
\hline \multicolumn{3}{|c|}{ Processing time (min), mean \pm SD } & $20.9 \pm 6.2$ & $22.7 \pm 7.8$ & $22.5 \pm 7.6$ & $>0.05$ \\
\hline
\end{tabular}




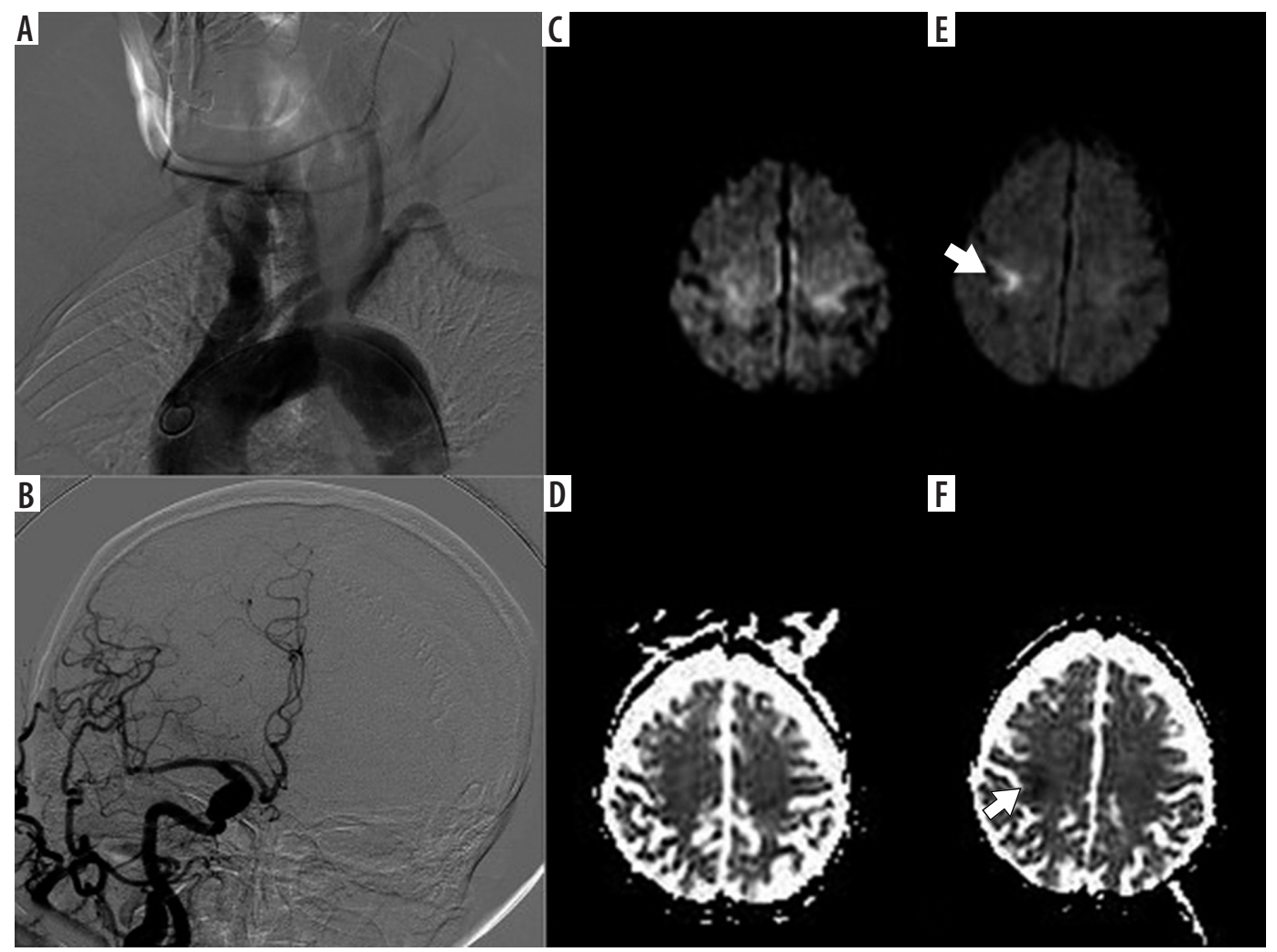

Figure 3. A, B) Used catheter SIM2 75-year-old male patient with type-2 and bovine aortic arch and non-selective catheterization angiography images of the common carotid artery. $C, D$ ) Before the procedure and (E, F) after the procedure diffusion-weighted imaging and ADC maps, $15 \mathrm{~mm}$ ischaemic lesion located in the subcortical, ipsilateral middle cerebral artery territories

cerebrovascular disease group - in 1 patient undergoing angiography due to transient ischaemic attack (TIA) and in 1 patient undergoing angiography due to pre-diagnosis of carotid cavernous fistula (CCF) (Table 2).

Four $(57.1 \%)$ of the patients with newly developed lesions according to DWI findings were males and $3(42.9 \%)$ were females $(p>0.05)$. The mean age of the patients with newly developed lesions according to DWI findings was $66.4 \pm 11.8$ years, while the mean age of patients without newly emerging lesions according to DWI findings was $53.7 \pm 14.9$ years $(p<0.05)$ (Table 3$)$.

Atherosclerosis was seen in $6(85.7 \%)$ of the patients with newly emerged lesions according to DWI findings ( $p>0.05)$. A SIM2 catheter was used in 5 (71.4\%) of them $(p>0.05)$ (Figure 3$)$ and the selective procedure was performed in $4(57.1 \%)(p>0.05)$. There was a normal arcus type in 4 patients $(57.1 \%)$, while there was bovine-type arcus in $3(42.9 \%)$. There were $2(28.6 \%)$ patients with type- 1 arcus, 4 (57.1\%) patients with type- 2 arcus, and 1 (14.3\%) patient with type-3 arcus $(p>0.05)$.

According to DWI findings, the mean amount of contrast agent was defined as $139.2 \pm 55.9 \mathrm{ml}$ in patients with newly developed lesions, while it was $148.9 \pm 36.2 \mathrm{ml}$ in patients without newly emerging lesions. Mean procedure duration was defined as $20.9 \pm 6.2 \mathrm{~min}$ for patients with newly developed lesions according to DWI findings, while it was $22.7 \pm 7.8 \mathrm{~min}$ for patients without newly developed lesions $(p>0.05)$ (Table 3$)$.

\section{Discussion}

Diagnostic angiography is an imaging modality accepted as the gold standard for vascular system imaging. The main indications for diagnostic angiography are to obtain more detailed information about cerebrovascular deficiency conditions due to an obstruction in the carotid or vertebrobasilar system or as a result of stenosis and vascular lesions and tumoural formations such as aneurysm, arteriovenous fistula (AVF), and arteriovenous malformation (AVM) [4]. The most typical indication is atherosclerotic occlusive cerebrovascular disease [1]. Seventy-one patients were included in this study, and diagnostic angiography was performed in 22 of these due to atherosclerotic vascular disease. This rate is consistent with the literature when assessed in terms of the patients' indication incidence. Technological advances have provided a significant reduction in DSA-related complications. Therefore, the examinations can be carried out in a shorter time, and fewer contrast agents are used. Moreover, softer catheters with various tip shapes have been produced owing to advances in catheterization technology, and the reduction in complications was contributed to this. The related risk factors leading to angiographic complications are reported as advanced age, presence of systemic disease, frequent catheter alterations, contrast agent quantity, long examination time, presence of cerebrovascular disease, frequent transient ischaemic attack, advanced carotid artery dis- 
ease, and examination performed by people without sufficient experience [5].

All kinds of intraarterial procedures have a risk of cerebral embolism [6,7]. Microscopic air embolisms do not present neurological symptoms, and thromboembolic changes cannot be detected with clinical examinations [6]. In the studies comparing stroke incidence, considering the detection of thromboembolic complications based on neurological examinations, it is impossible to demonstrate the incidence and the real sizes of thromboembolism. Today, there is a chance to obtain comprehensive information about the real size of the embolism by defining not only the macroembolic events presenting clinical symptoms but also clinically silent microembolic events with DWI, which is highly sensitive in revealing cerebral ischaemia in the early period. Embolic ischaemic events that are not revealed clinically can be detected in the first minutes with DWI [8]. On reviewing the literature, silent ischaemia incidence is between 5 and $23 \%$ on DWI following diagnostic angiography [9-11]. The study with the most extensive series on this subject was conducted by Krings et al. [12], and silent ischaemia was defined in $11.1 \%$ of the total of 107 patients. In this study, the asymptomatic ischaemic lesion incidence with DWI was $9.9 \%$, consistent with the literature. The number of lesions was 1-2 in $92.31 \%$ of the positive diffusion patients, mostly $6-10 \mathrm{~mm}$ size (53.85\%), and mainly located in MCA irrigation (69.23\%) and subcortical (69.23\%) areas. In their studies, Büsing et al. [13] and Bendszus et al. [14] found similar results for newly revealed DWI lesions. They stated the lesions were mostly single and had cortical location in the MCA territory, and the events were compliant with the embolic pattern. Similarly, in this study, the topographic distribution of the lesions supports the view that the embolic pattern is the primary mechanism.

In this study, a statistically significant difference was found between age and embolism development $(p<0.05)$. Although there was no statistically significant difference between the presence of atherosclerosis and new ischaemic lesion development $(p>0.05)$, this difference was numerically remarkable. Diffusion anomalies occurring after angiography were stated in the literature to depend on the patient factor and not to the procedure itself $[3,12]$. This conclusion suggests that the age of the patient and the presence of atherosclerotic lesions may cause an ischaemic lesion.

Atherosclerotic plaques, especially severe atherosclerosis of the aorta, are an essential risk indicator for thromboembolism $[14,15]$. In the study by Willinsky et al. [16], the neurological complication rate was demonstrated to increase prominently with age 55 years and over. They found the complication rate to be $1.8 \%$ in cases aged 55 years and over, while this rate was $0.09 \%$ in cases under 55 years old. In their series with 3636 cases, Fifi et al. [17] reported that the complication rate for diagnostic angiographies performed by an experienced neuroradiologist in a modern academic centre was $0.3 \%$ and the most critical risk factor was advanced age (65 years and over).

The mean age in this study was $55.97 \pm 15.04$ years. The mean age of the cases with newly emerged lesions, according to DWI findings, was $66.43 \pm 11.76$ years. When the presence or absence of development of new symptoms was compared with the ages of the cases, a statistically significant difference was defined between them $(p<0.05)$. Furthermore, while there was no atherosclerosis in 1 case (14.3\%) from the newly developed lesions according to the DWI findings group, 6 patients $(85.7 \%)$ in this group had atherosclerosis. This finding shows that age and atherosclerosis, which are essential factors in numerous literature reports, were also the most critical factors in our study in causing the diffusion anomalies. Many more diffusion anomalies in advanced age with atherosclerotic vascular structure suggest the development of procedural atheroembolism. Therefore, it was emphasized that catheterization techniques should be applied rigorously to prevent silent or symptomatic cerebral embolic ischaemia occurring following catheterization, particularly in atherosclerotic cases $[18,19]$.

In silent embolic ischaemia occurring following angiography, scratching the vessel wall and removing the atherosclerotic plaques were demonstrated. In interventional radiology, the catheters used for diagnostic purposes are preferred to have $5 \mathrm{~F}$ diameter. In addition, there are several studies indicating that the complication rate decreases with decreasing catheter diameter [20]. However, using catheters with a diameter of less than $4 \mathrm{~F}$ was reported to decrease the vascular opacification and prolong the procedure duration [21]. Thus, we chose to use a $5 \mathrm{~F}$ catheter in this study. Two types of catheters $(5 \mathrm{~F} \mathrm{H1}$ and 5F SIM2) were used in this study, and these were not altered. There is no specific study on the effectiveness of both the catheters. In the virtual simulation course, which is a new endovascular training method, Riddick et al. [22] compared complex (SIM2) and simple type catheters in difficult conditions for ischaemic stroke due to carotid catheterization. For the static and dynamic performance of the catheters, similarly to our study, they found that the procedure duration was longer with simple catheters than with SIM2, while there were numerically more vascular complications. However, the course participants found the performance of the SIM2 catheter to be better. There was a statistically significant difference between the ages of the cases regarding catheter use $(p>0.05)$. The SIM2 catheter was used in all type- 3 arcus with difficult catheterization, and $\mathrm{H} 1$ was not used in these cases. We believe the type-3 arcus seen more in elderly and atherosclerotic cases numerically increased the ischaemic lesion development following catheterization with SIM2.

Earnest et al. reported a clearly increased complication rate with the coexistence of diffuse atherosclerosis, tortuous vascular structure, and cerebrovascular disease along with catheter alterations, rather than the type and 
size of the catheter [23]. In this study, we did not evaluate the complications resulting from the catheter selection according to arcus type and catheter alterations.

Selective catheterization of ICA is known to increase the complication rate and to cause dissection [24]. In this study, new lesions were detected during 4 selective procedures and 3 nonselective procedures. However, there was no statistically significant difference between the groups with and without lesions emerging $(p>0.05)$, although a higher number of lesions developed in the selective procedures.

Arcus aorta types and outlet variations in the primary vascular structures may affect the interventional procedures. Type- 2 and type- 3 aortic arcus, and bovine type arcus may cause difficulties during catheterization. Moreover, complicated anatomies, like tortuosity, have an increasing effect on thromboembolic events because they increase the catheter manipulation [5]. There was complicated anatomy in 6 of our 7 cases who developed lesions $(p>0.05)$ in our study. Especially the effects of the type-2 and type- 3 arcus are seen more in the elderly and atherosclerotic population, and the results should be considered with caution based on the small number of our cases.

Contrast agent-related complications are systemic complications that depend on the toxicity of the contrast agent. Complication rates were significantly reduced with the use of nonionic contrast agents that have lower osmolality [5]. Bendzus et al. [10] reported the number of contrast agents in the groups without and with lesions as 110 and $149 \mathrm{~mL}$, respectively, and this difference was statistically significant.

The average amount of the contrast agent used in this study was $139.2 \pm 55.9 \mathrm{ml}$ in the groups without and with developed lesions, and this was more than in the study by Bendzus et al. This is because cerebrovascular lesions such as aneurysm, AVM, CCF, etc. were included in this study, and more images were acquired from various angles for better visualization of these lesions. The contrast agent amount used in the group in which lesions developed $(148.9 \pm 36.2)$ was consistent with the literature $(p>0.05)$.

The duration the catheter remains in the arterial structure is essential and directly associated with angiographyrelated complications [15]. In their study of 1517 patients in which the mean procedure time was $46 \mathrm{~min}$, Earnest et al. [23] found a statistical correlation between the complications and increases in age, contrast agent amount, and pro- cedure duration. The mean procedure duration was 22.49 $\pm 7.58 \mathrm{~min}$ in our study $(p>0.05)$. This depends on the determination of the catheters according to arcus type, using SIM2 catheter had high performance and technical competence of the operator. Moreover, the duration was stated to be a criterion reflecting the competence of the neuroradiologist who performs the procedure [25]. Another multicentre study included 5000 cerebral angiographies, and the complication rate was $3.9 \%$ in training hospitals and $0.9 \%$ in other hospitals. Complication rates were $1.8 \%$ for radiologists and $0.07 \%$ for neuroradiologists, and the difference between the 2 groups who performed the operations was statistically significant [26]. Because our procedures were performed by a single experienced neuroradiologist, a comparison between the operators could not be made.

There were no obvious systemic or local complications in this study. This suggests that a single specialist neuroradiologist contributed to the procedures. It is reported that if there is no alternative method to the diagnostic angiography in cases of high-risk situations like atherosclerosis and vasculitis, angiography performed by an experienced neuroradiologist decreases the silent embolism rate [12].

There is a general tendency to call lesions defined on DWI but not showing symptoms during routine neurological examination as silent ischaemia. However, in a study by Vermeer et al. [27], silent ischaemia was reported to cause cognitive impairment in the general population. Therefore, it is correct not to refer to these lesions as silent ischaemia, unless neurophysiological and neuropsychiatric tests are performed.

\section{Conclusions}

Diagnostic angiography procedure should be performed rigorously in the case population with cerebral embolism risk factors such as advanced age, atherosclerosis, and anatomical variants. Following angiography, DWI should be included in routine examinations, and the presence of silent ischaemia should be investigated. Applying neurophysiological and neuropsychiatric tests to cases in which silent ischaemia develops will provide more information about the importance of these lesions in the future.

\section{Conflicts of interest}

The authors declare that they have no conflicts of interest.

\section{References}

1. Helms CA. Fundamentals of diagnostic radiology. 3rd ed. Lippincott Williams \& Wilkins, Philadelphia 2007; 1070-1073.

2. Willinsky RA, Taylor SM, Ter Brugge K, et al. Neurologic complications of cerebral angiography: prospective analysis of 2,899 procedures and review of the literature. Radiology 2003; 227: 522-528.
3. Britt PM, Heiserman JE, Snider RM, et al. Incidence of postangiographic abnormalities revealed by diffusion-weighted MR imaging. Am J Neuroradiol 2000; 21: 55-59.

4. Osborn AG. Diagnostic cerebral angiography. 2nd ed. Lippincott Williams \& Wilkins, Philadelphia 1999: 117-151. 
5. Bakaç G, Yalçıner B, Kırbas D, Baybas S. Serebral anjiyografide komplikasyon oranları. Türk Nörosirurji Dergisi 2000; 10: 6-10.

6. Gupta R, Vora N, Thomas A, et al. Symptomatic cerebral air embolism during neuro-angiographic procedures: incidence and problem avoidance. Neurocrit Care 2007; 7: 241-246.

7. Tureli HO, Ungan I, Tureli D, et al. Risk of cerebral embolism after interventional closure of symptomatic patent foramen ovale or atrial septal defect: a diffusion-weighted MRI and neuron specific enolase based study. J Invasive Cardiol 2013; 25: 519-524.

8. Bartsch T, Deuschl G. Transient global amnesia: functional anatomy and clinical implications. Lancet Neurol 2010; 9: 205-214.

9. Hahnel S, Bender J, Jansen O, et al. Clinically silent cerebral embolisms after cerebral catheter angiography. Rofo Fortschr Geb Rontgenstr Neuen Bildgeb Verfahr 2001; 173: 300-305.

10. Bendszus M, Koltzenburg M, Burger R, et al. Silent embolism in diagnostic cerebral angiography and neurointerventional procedures: a prospective study. Lancet 1999; 354: 1594-1597.

11. Thiex R, Norbash AM, Frerichs KU. The safety of dedicated-team catheter-based diagnostic cerebral angiography in the era of advanced noninvasive imaging. Am J Neuroradiol 2010; 31: 230-234.

12. Krings T, Willmes K, Becker R, et al. Silent microemboli related to diagnostic cerebral angiography: a matter of operator's experience and patient's disease. Neuroradiology 2006; 48: 387-393.

13. Büsing KA, Schulte-Sasse C, Flüchter S, et al. Incidence and risk factors after diagnostic and interventional cardiac catheterizationprospective evaluation at DWI. Radiology 2005; 235: 177-183.

14. Rauch U, Osende JI, Fuster V, et al. Thrombus formation on atherosclerotic plaques: pathogenesis and clinical consequences. Ann Intern Med 2001; 134: 224-238.

15. Samim M, Hendrikse J, van der Worp HB, et al. Silent ischemic brain lesions after transcatheter aortic valve replacement: lesion distribution and predictors. Clin Res Cardiol 2015; 104: 430-438.

16. Willinsky RA, Taylor SM, Terbrugge K, et al. Neurologic complications of cerebral angiography: prospective Analysis of 2,899 procedures and review of the literature. Radiology 2003; 227: 522-528.
17. Fifi JT, Meyers PM, Lavine SD, et al. Complications of modern diagnostic cerebral angiography in an academic medical center. J Vasc Interv Radiol 2009; 4: 442-447.

18. Kumar S. Cerebral embolism after retrograde catheterization of aortic valve in aortic stenosis. Lancet 2003; 362: 78-79.

19. Omran H, Schmidt H, Hackenbroch $M$, et al. Silent and apparent cerebral embolism after retrograde catheterisation of the aortic valve in aortic stenosis. Lancet 2003; 361: 1241-1246.

20. Komiyama M, Nakajima H, Nishikawa M, et al. A 3.2-French cerebral diagnostic catheter for all ages: technical note. Am J Neuroradiol 2001; 22: 1602-1603.

21. Kiryosue H, Okahara M, Nagatomi H, et al. 3.3F catheter/sheath system for use in diagnostic neuroangiography. Am J Neuroradiol 2002; 23: 711-715.

22. Riddick JA, Patel AD, Helmy T, Cates CU. Metric-based virtual reality simulation detects performance differences in carotid angiography using a complex catheter versus a simple catheter. Circulation 2006; 114: II_819.

23. Earnest F, Forbes G, Sandok BA, et al. Complications of cerebral angiography: prospective assessment of risk. Am J Roentgenol 1984; 142: 247-253.

24. Shen J, Karki M, Jiang T, Zhao B. Complications associated with diagnostic cerebral angiography: A retrospective analysis of 644 consecutive cerebral angiographic cases. Neurology India 2018; 66: 1154-1158.

25. Grzyska U, Freitag J, Zeumer H. Selective cerebral intraarterial DSA: complication rate and control of risk factors. Neuroradiology 1990; 32: 296-299.

26. Mani RL, Eisenberg RL, McDonald EJ, et al. Complications of catheter cerebral arteriography: Analysis of 5,000 procedures. I. Criteria and incidence. Am J Roentgenol 1978; 131: 861-865.

27. Vermeer SE, Prins ND, den Heijer T, et al. Silent brain infarcts and the risk of dementia and cognitive decline. N Engl J Med 2003; 348: 1215-1222. 